\title{
Toezicht op financiële instellingen
}

\section{Deel 5: Pensioenfondsen en verzekeraars}

\author{
Dr. A.J. Vermaat
}

\section{Inleiding}

In deze aflevering staat het toezicht van de Verzekeringskamer op verzekeraars en pensioenfondsen centraal. In de volgende paragraaf wordt een compacte beschrijving gegeven van de aard van dit toezicht en de daarbij gebruikelijke toezichtsmethoden. Vervolgens wordt aandacht geschonken aan de actualisering van het toezicht (paragraaf 3). Daarna wordt in twee paragrafen gesplitst naar nationale en internationale thema 's ingegaan op lopende beleidsdiscussies, die aanleiding kunnen geven tot verdere modificaties van het toezicht (paragraaf 4 en 5). Ten slotte wordt in paragraaf 6 een korte slotbeschouwing gegeven, waarbij tevens commentaar wordt geleverd op de voorspellingen in het introductie-artikel van Oosenbrug (1997).

\section{Aard van het toezicht}

Het huidige wettelijke systeem van toezicht in de Nederlandse verzekeringsbedrijfstak is in 1923 begonnen met de levensverzekeraars.' Later is het bereik van dit toezicht uitgebreid tot pensioenfondsen en schadeverzekeraars (en recentelijk tot natura-uitvaartverzekeraars). Hoewel er uiteraard onderling verschillen qua toezichtsregels en methoden bestaan (vanwege de specifieke karakteristieken), gaat het in alle gevallen om een vorm van zogenoemd normatief/repressief toezicht. Dit type van toezicht wordt gekenmerkt door het stellen van bepaalde wettelijke (globale) normen vooraf en het achteraf toetsen op de naleving ervan door de toezichthouder. De vergunninghoudende ondernemingen wordt hierbij zoveel mogelijk beleidsvrijheid gelaten, zodat een sterke marktwerking kan ontstaan.
Het normatieve toezichtsstelsel staat in tegenstelling tot het materiële toezicht dat in de meeste Europese landen gangbaar is (geweest). Bij dit laatste moeten de verzekeraars vooraf de toestemming vragen van hun toezichthouder over alle nieuwe producten, premies en polisvoorwaarden. Per saldo leidt het materiële toezichtsstelsel tot hogere tarieven, minder innovatie en productdifferentiatie omdat de concurrentiemarges in de praktijk smaller uitvallen. De kans op insolventies zal in dat geval echter kleiner zijn.

De binnen het normatieve toezicht gestelde normen zijn zoveel mogelijk bij of krachtens de wet bepaald. Binnen dit kader beschikt de toezichthouder over enige discretionaire beleidsruimte, omdat in de praktijk binnen een gegeven categorie significante verschillen optreden. Het voldoen aan de wettelijke normen is noodzakelijk om het verzekerings- of pensioenbedrijf te mogen uitoefenen. Deze eisen hebben onder meer betrekking op de volgende zaken:

- de rechtsvorm (bij verzekeraars de naamloze vennootschap of de onderlinge waarborgmaatschappij, bij pensioenfondsen meestal de stichtingsvorm);

- het verbod van nevenbedrijf (inclusief splitsing tussen levens- en schadeverzekeraars; wel zijn binnen groepen verschillende soorten bedrijven toegestaan);

- de minimale omvang van het aansprakelijk

Dr. A.J. Vermaat studeerde algemene economie aan de Vrije Universiteit te Amsterdam, promotie in 1966. Hij vervulde diverse functies in het hoger onderwijs, onder meer hoogleraar Economische Politiek \& Economische Orde. Sinds 1988 is hij voorzitter van de Verzekeringskamer. 
vermogen (bij verzekeraars is dit de vereiste solvabiliteitsmarge, die varieert met de aard van het bedrijf, de branche en de omvang); - de toetsing van het beleggingsbeleid.

Daarnaast bestaan er specifieke materiële bepalingen in de relevante toezichtswetten, ${ }^{2}$ zoals bijvoorbeeld bepaalde informatieverstrekking door levensverzekeraars. De essentie is dus dat er globaliter sprake is van een - zeker vergeleken met het buitenland - relatief zeer substantiële beslissingsvrijheid van de onder toezicht staande instellingen.

Alvorens in te gaan op de gebruikelijke toezichtsmethoden in het kader van een normatief/ repressief toezicht enkele data over de verschillende soorten van betrokken instellingen in Nederland.

Tabel 1: Nominaal aantal verzekeraars en pensioenfondsen (ultimo 1996) ${ }^{3}$

(i) Pensioenfondsen

- verplichte bedrijfspensioenfondsen 68

- niet verplichte bedrijfspensioenfondsen 15

- ondernemingspensioenfondsen 979

- ondernemingsspaarfondsen 8

- beroepspensioenfondsen 11

Sub-totaal (i)

(ii) Verzekeraars

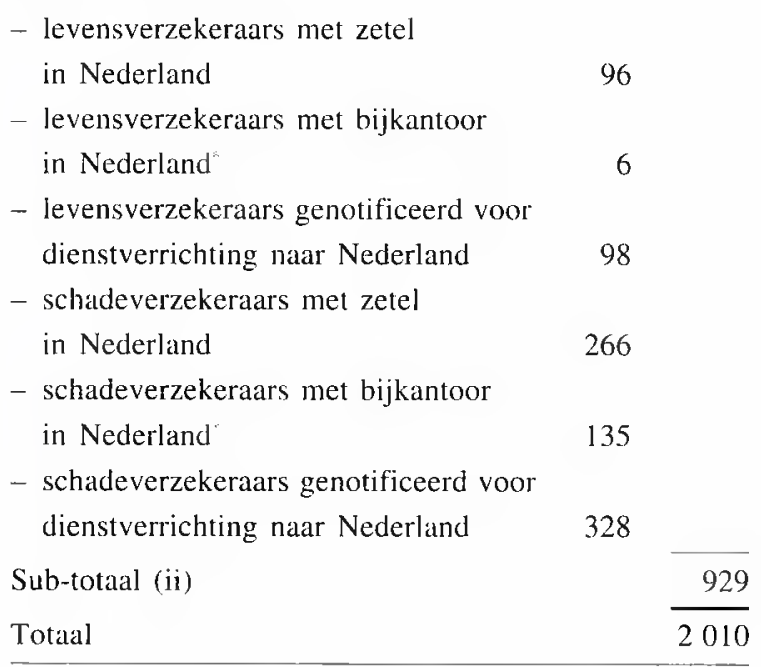

Het betreft bijkantoren van niet-EER verzekeraars

De aard van de gehanteerde toezichtsmethoden hangt uiteraard nauw samen met het karakter van het normatief/repressieve toezichtsstelsel. Naast de toetsing van specifieke materiële wettelijke bepalingen (relatief het sterkst bij pensioenfondsen) gaat het hierbij primair om solvabiliteitstoezicht. De belangrijkste instrumenten weerspiegelen dit. Het is evident dat er continu wijzigingen in het toezichtsinstrumentarium optreden. Recentelijk is een majeure instrumentale innovatie in gang gezet (zie paragraaf 3 ).

Naast incidenteel optreden van de toezichthouder gaat het vooral om de periodieke toezichtsactiviteiten. Incidenteel optreden - meestal per instelling, maar soms betrokken op een branchegroep of conglomeraat - heeft te maken met de vergunningverlening (verzekeraars) of registratie (pensioenfondsen respectievelijk de notificatie van buitenlandse verzekeraars), dan wel met specifieke problemen bij een onder toezicht staande instelling. De belangrijkste periodieke toezichtsactiviteiten bestaan uit de periodieke analyse van de door de instellingen ingezonden financiële staten, ${ }^{4}$ het algemene respectievelijk gerichte onderzoek op locatie, het periodieke beleidsgesprek met bestuurders van de instellingen en hun professionele adviseurs, de toetsing van het beleggingsbeleid $^{5}$ en de beoordeling van de financiële gevolgen van wijzigingen in statuten/reglementen, financieringsovereenkomsten en andere strategische beleidsstukken.

Bovendien vindt er profit-testing (achteraf) van levenproducten plaats, en worden de bestuurders van verzekeraars op deskundigheid en betrouwbaarheid en hun commissarissen op betrouwbaarheid getoetst. Levert een dergelijke 'routine'activiteit een waarschuwingssignaal op, dan volgt uiteraard een meer gerichte actie. In dit verband is het sterke informatierecht van de Verzekeringskamer op de instellingen inclusief verwante entiteiten (het zogenoemde 'droit de suite') van belang. Tot zover deze indicatieve opsomming. ${ }^{6}$

Ten slotte nog enkele opmerkingen over de verschillen/overeenkomsten tussen verzekeraars en pensioenfondsen. Qua wetgeving, toezichtsregimes en toezichtsmethoden bestaan er inderdaad niet onbelangrijke verschillen tussen beide groepen financiële instellingen. Dit onderscheid is terug te voeren op de verschillende aard en maatschappelijke functie.

Een verzekeraar opereert op een concurrentiële markt, waardoor er in het algemeen slechts sprake kan zijn van de realisatie van kanssolidariteit, ${ }^{7}$ 
terwijl ook de corporate governance-structuur meer door marktkrachten wordt bepaald. Bij pensioenfondsen ligt vanouds een sterker accent op het verzorgingsmotief en op de realisatie van inkomens- respectievelijk generationele solidariteit. zodat er slechts een indirecte competitie aanwezig is en ook de corporate governance-structuur meer intern gericht is. Op grond hicrvan ziet men een onderscheid qua wetgeving en formele eisen, bijvoorbeeld ten aanzien van rechtsvorm en andere registratie-eisen, fiscale behandeling. verplichte verslaggeving en vereiste informatieverschalfing aan polishouders/deelnemers.

Ook de toezichtsregimes vertonen verschillen die hierop aansluiten. Voor pensioenfondsen gelden bijvoorbeeld geen wettelijk vereiste solvabiliteitsmarges. Ook is er geen sprake van bestuurderstoetsing ${ }^{\times}$en profït testing. Daarentegen gelden er voor pensioenfondsen juist verdergatande materiële eisen terzake van gelijke behandeling. pensioenrechten bij ontslag. et cetera. Een zeer substantieel verschil vormt hel sanctie-instrumentarium. dat ten aanzien van de pensioenfondsen momenteel nagenoeg ontbreekt. ${ }^{9}$ Overigens tracht de Verzekeringskamer de toezichtsmethoden voorzover mogelijk naar analogie vorm te geven. Dit kan men bijvoorbeeld zien in de opzet van de zogenoemde Actuariële Principes Leven en de Actuariële Principes Pensioenen.

\section{Actualisering toezicht}

Net als in andere delen van de samenleving was er in het afgelopen decennium ook in de bedrijlstak verzekeren \& pensioenen sprake van een zich verhevigende dynamiek. Voor een deel gaat het daarbij om wereldwijde ontwikkelingen. bijvoorbeeld op het terrein van technologie (vooral IT). demografie (vergrijzing). moraliteitswijzigingen. economische liberalisering en globalisering.

Daarnaast is de toegenomen concurrentie terug te voeren op (supra)nationale politieke en sociale ontwikkelingen. Hierbij gaat het niet alleen om nationale besluiten, maar niet minder om op het niveau van de Europese Unie (respectievelijk EER) ingezelte veranderingen. Van dit laatste zijn belangrijke voorbeelden de diverse richılijnen voor verzekeraars ter realisering van één Europese verzekeringsmarkt. hel gevoerde Europese mededingingsbeleid en de daarbij behorende anticiperende (re)acties van economische groepen.
Het nationale beleid sluit hierop alan. zoals bijvoorbeeld blijkı uil de aangescherpte mededingingspolitiek (bekroond met de nieuwe Mededingingswet per 1-1-1998) en de maatregelen in het kader van de MDW-operatie. Daarnaast zorgen ook de toenemende individualisering. de beëindiging van vormen van zelfregulering. de wetgeving gericht op een betere bescherming van de burger/ consument respectievelijk de aanscherping van de aansprakelijkheidswetgeving en -rechtspraak voor cen scherpere concurrentie voor verzekeraars en pensioenfondsen.

De verheviging van de concurrentie en de alanscherping van de toezichtswetgeving - zowel op Europees als op national niveau - hebben geleid tot een systematische actualisering van het toezicht door de Verzekeringskamer op verzekeraars en pensioenfondsen. ") De implementatie van dit actualiseringsproject vergt uiteraard enige tijd en tevens een uitbreiding van het medewerkersbestand. In de periode 1997-2000 krijgt het project gestalte.

Kernelementen van de operatie zijn:

- meer geprofileerde alandacht voor de risicofactoren;

- zoveel mogelijk prospectieve inkleuring van de analyses:

- gedifferentieerde benadering van instellingen en problemen:

- vermijden van dubbel controlewerk (maximaal gebruik maken van het werk van andere professionals zoals accountants, actuarissen, EDP-auditors et cetera): en

- samenwerking met andere toezichthouders in bimnen-en buitenland.

In termen van het toezichtsinstrumentarium gaat het vooral om de volgende maatregelen:

- betere benutting van de informatie over instellingen door een verdere systematisering en optimaal toegankelijke (eigen) databanken;

- vervroegde indiening van de financiële staten;

- vaker opvragen van prognoses en strategische beleidsplannen;

- ontwikkeling van early warning en kennissystemen:

- differentiatie in toezichtsactiviteiten (zowel in de financiële analyse als in periodiek overleg en locatieonderzoek):

- uitbreiding van het periodiek beleidsoverleg met de instellingen; 
- ad hoc generieke schriftelijke onderzoeken:

- kadervoorschriften voor de administratieve en controlprocedures van de instellingen:

- modernisering van de Actuariële en Bedrijfstechnische notal voor pensioenfondsen;

- aanscherping van de bestuurderstoets voor verzekeraars respectievelijk de mogelijke invoering van een analoge toets voor pensioenfondsen: en

- het sluiten van overeenkomsten tussen de toezichthouder, de financiële instellingen en de betrokken accountants en actuarissen ter optimalisering van de informatiestromen. ${ }^{11}$

Ook voor wat betreft de sancties van het verzekeringstoezicht staat een aantal aanpassingen op stapel. Enkele voorbeelden: invoering van boetes en dwangsommen, aanwijzingsrecht in de PSW. intensiever gebruik van stille bewindvoerders of verplichte externe deskundigen bij de instellingen. Bestudeerd worden de mogelijkheden om een betere informaticuitwisseling te scheppen tussen de financiële toezichthouders en de juridische opsporingsdiensten (OM, FIOD, ECD) respectievelijk inzage in de politiedossiers.

Verder wordt gewerkt aan een sterkere positie van de financiële toezichthouders in beroepsprocedures van 'afgetoetste bestuurders. Ten slotte verdient in dit verband nog de opvangregeling voor levensverzekeraars vermelding.

\section{Nationale toezichtsthema's}

In deze paragraat wordt aandacht besteed aan vier overwegend nationale thema's (uiteraard met deelvraagstellingen), die in de komende jaren waarschijnlijk aanleiding zullen geven tot wijzigingen in het toezicht:

a financiële conglomeraten;

b publiek/private samenwerking;

c consumentenbescherming;

d corporate governance.

\section{Ad a financiële conglomeraten}

Sinds het einde van de jaren tachtig hebben financiële conglomeraten (meestal gedefinieerd als een financieel-economische groep met ten minste twee van de volgende drie soorten instellingen: bank. verzekeraar, effectenbedrijf) sterk aan belang gewomnen in de Nederlandse financiële sector. Dit geldt eveneens in toenemende mate voor de Europese landen. maar niet voor de USA en Japan. De specifieke toezichtsrisico's die met de vorming van dergelijke conglomeraten gepaard gaan. vergen een passend antwoord van de tïnanciële toezichthouders. Nederland loopt in deze ontwikkeling voorop, mede door de protocolafspraken tussen de Nederlandsche Bank en de Verzekeringskamer.

Naast het uitgangspunt dat elke toezichthouder altijd het voorgeschreven aparte solotoezicht blijft uitoefenen op de "eigen" instellingen, voorziet het Nederlandse model in een gezamenlijke aanpak van de echte gemengde financiële conglomeraten. DNB en Verzekeringskamer maken samen een periodieke analyse van de vereiste financiële kengetallen en werken samen bij de beoordeling van de wettelijk vereiste 'verklaring-van-geenbezwaar"-aanvragen voor gewenste participaties. Daarnaast letten beide toezichthouders op de gewenste transparantic en informatiestromen binnen de groep en de uitwisseling van de gegevens van de bestuurderstoetsen. In deze systematiek staat noch de niet-gelicentieerde (top)holding noch de groep als geheel onder toezicht. Wel zijn er op specifieke punten wettelijke bevoegdheden jegens de holding. Recentelijk lopen er discussies hoe binnen dit zogenoemde solo-plustoezichtsmodel de beoordeling van de treasury-functie respectievelijk het risicomanagement van de groep kunnen worden ingevuld.

\section{Ad b publiek/private samenwerking}

Naast financiële conglomeraten ontstaan er steeds meer heterogene en complexe groepen in ons land. Pensioenfondsen beginnen hiervan deel uit te maken, maar ook organisaties die meer als publiekrechtelijk kunnen worden gekarakteriseerd, zoals ziekenfondsen en uitvoeringsinstellingen (uvi's) van de sociale zekerheid. Het ziet er naar uit dat in dit opzicht allerlei hybride vormen van financiële groepen gevormd worden. Dit creëert voor toezichthouders nieuwe problemen. ${ }^{12}$ Niet alleen verschillen de wettelijke taken en bevoegdheden van de diverse toezichthouders, maar ook het soort toezicht is verschillend. Bij particuliere financiële instellingen die onderhevig zijn alan de tucht van de markt is het toezicht primair bedrijlseconomisch gericht. Bij instellingen die werken met publieke middelen (en soms bovendien nog onderworpen worden aan enige vorm van 'marktwerking') ligt het accent daarentegen op rechtmatigheids- en doelmatigheidstoezicht. Het vinden 
van een optimale organisatie van het vereiste toezicht en efficiënte toezichtmethodes (zonder lacunes of te veel overlappingen) zal nog veel voeten in de aarde hebben.

\section{Ad c consumentenbescherming}

Mede ten gevolge van de toegenomen aandacht voor de burger als consument - ook gevoed door technologische impulsen, Europese regelgeving met het oog op de eenwording van de Europese markt en concentratieverschijnselen in de marktsector - verhevigen de discussies zich over de gewenste beschermingsregels. Hoewel men in het algemeen de burger mondiger acht (meer kennis en opleiding, meer infomogelijkheden. meer financiële middelen om kennis te kopen, et cetera) neemt de consumentenbescherming per saldo toe. ${ }^{13}$

Naast voorschriften omtrent inhoud, vorm en tijdstip van te verschaffen informatie (bijvoorbeeld over te sluiten polissen) gaat het ook om de marktpositie van de consument. Men ziet dit in het nieuwe mededingingsbeleid, de discussie over de (afschaffing van de) Wet assurantiebemiddelingsbedrijf (Wabb) en de discussie over de flexibilisering respectievelijk verplichte keuzemogelijkheden in de pensioenregelingen. Hierop sluiten ook de strengere en uitgebreidere eisen ten aanzien van de publieke verslaggeving van verzekeraars en (vooral) pensioenfondsen aan.

\section{Ad d corporate governance}

Met name de rapportage van de CommissiePeters heeft de discussie over corporate governance sterk gestimuleerd in Nederland. Beknopt geformuleerd gaat het daarbij om de 'disciplinering' van de onderneming; zowel intern als langs externe weg (dus inclusief wettelijk toezicht), zowel formeel als informeel.

Hoewel het in eerste instantie gaat om de structuurvennootschappen en vooral de officiële beursgenoteerde vennootschappen, kan deze thematiek een veel verdergaande uitwerking krijgen. Juist omdat in onze variant van het Rijnlandse model nogal wat disciplineringsdrempels bestaan, kan de aanrollende Angelsaksisch geïnspireerde golf pro aandeelhoudersrechten de komende jaren substantiële effecten hebben.

Macro-economisch gezien is er in toenemende mate sprake van globalisering, deregulering en monetaire integratie, terwijl de krachtsverhouding tussen kapitaal en arbeid mede daardoor verschuift. Een dominantere rol van de kapitaalverschaffers, een grotere volatiliteit op het terrein van kopen/verkopen van (onderdelen van) bedrijven en het opvoeren van geëiste nettorendementen zullen de concurrentie binnen de verzekeringsbedrijfstak op termijn nog verhevigen, zeker gezien tegen de achtergrond van de aanscherping van het algemene mededingingsbeleid. ${ }^{14}$

\section{Internationale toezichtsthema's}

Op dit terrein is gekozen voor de volgende onderwerpen:

I harmonisatie van de Europese verzekeringssector;

2 de relatie tussen financieel toezicht en mededingingstoezicht;

3 de samenwerking tussen financiële toezichthouders.

\section{Ad I harmonisatie van de Europese verzekeringssector}

Dé ene geïntegreerde verzekeringssector bestaat nog niet in de Europese Unie. Toch worden in de tweede helft van de jaren negentig substantiële stappen in die richting gezet. Met name de Derde Richtlijn Schade respectievelijk Leven, maar ook specifieke richtlijnen zoals de BCCI-Richtlijn, de Richtlijn Jaarverslaggeving verzekeringsondernemingen en de Richtlijnen Wettelijke Aansprakelijkheid Motorrijtuigen, hebben meegewerkt aan het verlagen van de drempels tussen de lidstaten. Nabij de grenzen en in het geval van grote risico's respectievelijk grote marktpartijen beginnen de concurrentiekanalen te 'communiceren'.

Om dit alles te effectueren is ook het toezicht geharmoniseerd. Weliswaar nog niet integraal, maar op een dusdanig niveau dat het toezicht geen aparte belemmering mag opwerpen voor de totstandkoming van één Europese markt. Hierbij let de Europese Commissie op de nationale wetgeving teneinde protectionistische elementen op te sporen en te verbieden (zonodig via het Europese Hof). Van groot belang is in dit verband dat in de derde generatie richtlijnen cruciale begrippen als 'single license' en 'home country control' (inclusief de afbakening/coördinatie tussen verzekeringstoezichthouders) zijn overgenomen. Ook het in Engeland en Nederland gebruikte normatieve toezichtsstelsel is overgeno- 
men. De keuze voor dit 1oezichtsstelsel bevordert de concurrentie op de verzekeringsmarkt vanwege de substantieel grotere beleidsvrijheid van ondernemers hierbij in vergelijking tot het in de overige EU-lidstaten gebruikelijke materiële toezichtsstelsel (zie paragraaf 2). Voor een volledig geïntegreerde verzekeringsmarkt zullen echter verdergaande wettelijke maatregelen nodig zijn, zoals de harmonisering van het contractenrecht en de belastingwetgeving.

\section{Ad 2 de relatie tussen financieel toesicht en} mededingingstoe-icht

Het Europese mededingingsbeleid is te typeren als een verbodswetgeving gericht op het tegengalan van elke ongewenste machtsvorming op markten respectievelijh ongewenste machtsuitoefening. De belangstelling richt zich vooral op:

- fusies, overnames, participaties, kartelafspraken etc. en

- vormen van afgestemd gedrag.

In de meeste lidstaten vindt een aanscherping van de nationale mededingingswetgeving platats. waarbij steeds meer aansluiting wordt gezocht bij het EU-beleid. Ondoorrichtig is momenteel hoe de uitbreiding van het mededingingstoezicht zich gaat verhouden tot het linanciële toezicht, dat in verschillende landen vanouds eveneens een taak had ten aanzien van de gezonde concurrentieverhoudingen in de financiële sectoren. Extra complicaties hierbij zijn de zeer uiteenlopende wettelijke taken op dit terrein in de lidstaten. de verschillen in de organisatie van het mededingingstoezicht in de lidstaten en het ontbreken van afstemmingsprocedures. Het lijkt logisch om meer helderheid en uniformiteit te creëren bij de afstemming van beide soorten van toezicht.

Interessint in dit verband is nog dat in het Verenigd Koninkrijk een reorganisatie lijkt te leiden tot twee clusters van toezicht:

a het financiële toezicht gericht op de soliditeit van de instellingen, en

b het overige toczicht gericht op elementen van directe consumentenbescherming. inclusief het marktgedrag van de fïnanciële instellingen.

\section{Ad 3 de samenwerking tussen financiële toe-ichthouders}

Dit thema wordt eveneens belicht vanuit het EU-gezichtspunt. De samenwerking tussen verzekeringstoezichthouders is goed geregeld. Van groot belang is daarbij het (in 1997 geactualiseerde) Protocol (inclusief de dric EER-landen).

Hiemaast kunnen nog bilaterale Memoranda-ofUnderstanding functioneren. Net als in ons land bestaan in de meeste EU-landen samenwerkingsafspraken tussen de diverse soorten van financiële toezichthouders. Vanuit Nederland wordt daarbij het 'toezichtsprotocol' van het solo-plusmodel geëxporteerd.

Verder is al enige tijd in discussie een conceptrichtlijn van de EU met betrekking tot het toezicht op fïnanciële conglomeraten. Dit vordert minder snel dan oorspronkelijk was voorzien. In de eerste plaats omdat de behandeling van de richtlijn toezicht verzekeringsgroepen meer lijd vergt en in de tweede plaats ondat de Europese Commissie een preferentic heeft voor het nauw aansluiten op de resultaten van internationaal overleg. Dit laatste vindt momenteel plats in het zogenoemde Joint Forum (waarin ook Nederland participeert), een gemeenschappelijk werkoverleg van de IOSCO (effectentoezichthouders), het BaselComité (bancaire toezichthouders) en de IAIS (verzekeringstoezichthouders).

Naast aambevolen toezichtsprincipes voor internationaal opererende fïnanciële conglomeraten staan daarbij ook coördinatieafspraken tussen toezichthouders ter bespreking. De IAIS-leden vinden dat op dit vlak ten minste minimumafspraken zouden moeten worden aumbevolen. ${ }^{15}$ Van groot belang voor een dergelijke meer-gecoördineerde wijze van samenwerking tussen diverse toezichthouders is hel elimineren van de bestande beperkingen op hel vrijelijk onderling uitwisselen van vertrouwelijke gegevens. Binnen de EU (EER) is dit reeds aldoende wettelijk geregeld. maar met name de Verenigde Staten liggen hierbij nogal ecns dwars. Vooral met het oog op de toegenomen globalisering zullen de nationale wetgevers en toezichthouders hierop passende antwoorden dienen te geven.

\section{Slotbeschouwing}

Het voorgande moge illustreren dat er veel dynamiek zil in de bedrijfstak, zowel nationaal als internationaal. Het toezicht is daarom ook volop in beweging. Wetgever en uitvoerende toezichthouders moeten voortdurend nicuwe antwoorden formuleren. Het is zalak hierbij de aard van het normatief/repressieve systeem geen geweld aan te 
doen, ook al zijn meer materiële voorschriften in sommige gevallen onontkoombaar. Naast beleidsconsistentie is het bovendien noodzakelijk dat er praktisch toepasbare en efficiënte toezichtsinstrumenten worden ontwikkeld. Het toezicht leidt tot directe en indirecte kosten - die uiteindelijk ten laste komen van de consument - zodat er steeds gezocht moet worden naar een optimum tussen baten en lasten.

In-beweging-zijn wil nog niet zeggen dat binnen korte termijn geheel nieuwe modellen en methoden voor de deur staan. Dat is ook lang niet altijd nodig. Daarom nog enig commentaar op de wat uitdagende voorspellingen van Oosenbrug in het openingsartikel van deze MAB-serie over het financiële toezicht. Typerend voor zijn opstelling is het volgende citaat: 'Vroeg of laat zal dit uitmonden in het ontstaan van één overkoepelende nationale toezichthouder per land/regio, die - al dan niet in de vorm van een "federatief" samenwerkingsverband - deel zal uitmaken van één internationaal toezichtsnetwerk.' (Oosenbrug, 1997. p. 226). Gezien de huidige ontwikkelingen van internationalisering en branchevervaging acht hij deze ontwikkeling uiteraard ook wenselijk (en vermoedelijk liever eerder dan later).

Los van het feit dat internationale afspraken zelfs bij taaie en creatieve onderhandelaars veel tijd kosten, wil ik een aantal relativerende opmerkingen maken. De door Oosenbrug beschreven branchevervaging in de financiële sector bestaat eigenlijk slechts in de ogen van de consument. Immers, het assemblerende front-office is niet identiek met de allocatie naar de producerende back-offices. Echte overlappingen van toegestane producten uit aparte sectoren komen nog weinig voor. Analogieën qua toezichtsmethoden zijn wenselijk, maar slechts voorzover deze logisch voortvloeien uit de aard van de business. Er bestaan nog steeds belangrijke verschillen tussen het reguliere bancaire bedrijf en het produceren van verzekeringen. Dan is het ook zinvol om de formules voor de vereiste solvabiliteitsmarges daarop te laten aansluiten.

Ongelijke level playing fields en verschillen in toezichtsarbitrage zijn niet altijd onwenselijk: ook dit hangt weer af van eventuele fundamentele verschillen in de bedrijfsaard. Daarom is het te simpel om zonder nadere reserveringen het idee van één financiële toezichthouder plus één toezichtsmethodiek voor te staan. De juiste set van toezichtsmethoden is primair in mijn ogen. Vervolgens komt de uitvoering door op het betreffende terrein gespecialiseerde deskundigen, en daarna komt pas de vraag hoe men dit toezichtswerk institutioneel vormgeeft.

Eén instituut heeft stellig praktische voordelen. maar ook nadelen. Een internationale harmonisatie naar één uniforme toezichtsmethodiek is nog veel moeilijker. Het voorbeeld van Oosenbrug van het Bazelse akkoord is weinig gelukkig. Internationaal lijkt er overeenstemming te ontstaan dat het zogenoemde model van geconsolideerd toezicht niet toepasbaar is voor financiële conglomeraten, laat staan voor de nieuwe nog heterogenere groepen.

Krijgt Oosenbrug dus geen gelijk? Voorzover het een voorspelling inhoudt, is de formulering 'vroeg of laat' nogal immuniserend, dus moeilijk te falsificeren. Voorzover het een visionaire wenselijkheid uitdrukt, lijkt mij de praktische slogan 'first things first' een betere leidraad!

\section{I T E R A T U U R}

Broeke, P.v.d., (1997), Hybride organisaties en verzekeringstoezicht: business as usual?, Pensioen Magazine, november, pp. 28-33.

Oosenbrug, A., (1997), Het bedrijfseconomische toezicht op financiële dienstverleners nu en in de 21ste eeuw, MAB, mei, pp. 215-228.

Vermaat, A.J. en A. Oosenbrug, (1994), Bedriffseconomisch toezicht op verzekeraars en pensioenfondsen, Delwel, Den Haag.

Vermaat, A.J., (1997), Insurance Company Ownership in the Netherlands: Implications for Corporate Governance and Competition, Verzekeringskamer, Apeldoorn.

Verzekeringskamer, (1997), De actualisering van het toezicht, Apeldoorn.

\section{N O T E N}

1 In 1923 werd de Wet op het levensverzekeringsbedrijf van kracht. In dat jaar werd ook de Verzekeringskamer opgericht. Hoewel er een relatie bestond met het departement van Justitie was de Verzekeringskamer toen reeds een soort van 'zelfstandig bestuursorgaan' avant la lettre. Dit was een duidelijke keus van de wetgever. Men wilde het prudentiële toezicht niet laten beïnvloeden door allerlei andere politieke 
afwegingen. Ook speelde hierbij een rol de poging van minister Treub tijdens de Eerste Wereldoorlog de levensverzekeringsmaatschappijen te nationaliseren. Met de verzelfstandiging van de Verzekeringskamer in 1992 tot een (bijzondere) privaatrechtelijke stichting is deze oorspronkelijke lijn doorgezet. Momenteel werken er circa 130 personen bij de Verzekeringskamer, terwijl het budget voor 199727 miljoen gulden bedraagt.

2 Als belangrijkste toezichtswetten zijn te noemen:

a voor de verzekeraars de Wet toezicht verzekeringsbedrijf 1993 en de Wet toezicht natura uitvaartverzekeringsbedrijf;

b voor de pensioenfondsen de Pensioen- en spaarfondsenwet, de Wet verplichtstelling bedrijfspensioenen en de Wet verplichtstelling beroepspensioenfondsen.

3 Bron: Verzekeringskamer 1997. Nog niet opgenomen zijn de natura-uitvaartverzekeraars (ultimo 1996 geschat op circa 70) in verband met de invoeringsbepalingen van de Wtn. Evenmin zijn opgenomen in deze tabel de per ultimo 1996251 werkzame kleine van toezicht vrijgestelde onderlinge schadeverzekeraars. In het geheel niet onder toezicht staan in ons land de professionele herverzekeraars die niet het directe verzekeringsbedrijf uitoefenen. Evenmin staan de assurantietussenpersonen noch de pensioen-BV's van dga's onder toezicht van de Verzekeringskamer.

4 Tevens wordt gewerkt met een signaleringssysteem op grond waarvan de prioriteitstelling van de behandeling van de ontvangen financiële staten wordt vastgesteld.

5 Voor verzekeraars is hierbij nog van belang de verplichting om voor (duurzame) participaties, welke bepaalde drempels overschrijden, een zogenoemde verklaring-van-geenbezwaar te verkrijgen.

6 Zie voor een bredere uiteenzetting Vermaat \& Oosenbrug (1994) en voorts de Algemene Jaarverslagen van de Verzekeringskamer.

7 Bij kanssolidariteit is er ex ante sprake van een equivalentie per deelnemer tussen prijs en verwachte schade; ex post is er uiteraard solidariteit van de premiebetalers met degenen die een schade-uitkering ontvangen. Bij de subsidiërende (inkomens/intergenerationele) solidariteit is er ex ante géén sprake van equivalentie maar van subsidiëring.

8 Het is overigens zeer waarschijnlijk dat in de nabije toekomst ook de bestuurders van pensioenfondsen aan een analoge toets zullen worden onderworpen

9 Hieraan wordt overigens momenteel hard gewerkt in het kader van een beoogde wijziging van de Pensioen- en spaarfondsenwet door SZW

10 Zie Verzekeringskamer (1997).

11 Hiertoe is op 10-10-1997 een tripartiete protocol ondertekend tussen de Verzekeringskamer, het Verbond van verzekeraars en het Koninklijk NIVRA. Andere analoge overeenkomsten zullen worden afgesloten met het Actuarieel Genootschap respectievelijk de koepelorganisaties van de pensioenfondsen.

12 Zie hierover bijvoorbeeld Van de Broeke (1997).

13 De overheid is overigens bij dit dossier niet altijd even consequent. Zo kan bij een aantal op stapel staande maatregelen in het kader van de MDW-operatie terdege worden getwijfeld of die de belangen van de consument zullen dienen.

14 Zie Vermaat (1997).

15 In het algemeen onderscheidt men de volgende zeven activiteiten in het kader van de samenwerkingsvormen tussen de toezichthouders die betrokken zijn bij een internationaal financieel conglomeraat:

a 'mapping' van het conglomeraat,

b 'listing' van de betrokken toezichthouders en hun taken,

c 'convening' van de meest betrokken toezichthouders,

d organisering van de benodigde informatie met betrekking tot het gehele conglomeraat,

e analyseren van de financiële soliditeit ervan,

$f$ arrangeren aan eventuele maatregelen door bepaalde toezichthouders en

$g$ publiciteitstaken.

De IAIS is van mening dat voor elk belangrijk financieel conglomeraat ten minste de eerste drie activiteiten verplicht dienen te worden afgesproken. 